\title{
Glaucoma screening
}

Chronic glaucoma, recognised as the 'silent destroyer', can be expected to increase in prevalence with an aging population. ${ }^{1}$ The cost of blindness from glaucoma (based on Royal National Institute for the Blind (RNIB) blindness figures, tax losses, and an annual social security payment of $£ 2700$ ) will exceed $£ 100$ million annually. As the true blindness figures are likely to exceed the RNIB total the national cost of blindness from glaucoma will exceed this figure. Earlier detection offers the best chance of blindness prevention, especially after the demonstration that treatment given early gives the best prognosis ${ }^{2}$ and that adequate intraocular pressure (IOP) lowering can halt progression. ${ }^{3}$

To date efforts to achieve visual preservation by case finding have relied on increasing public awareness, case detection by opticians, and a greater referral rate of suspects, particularly those with a positive family history, by general practitioners. Despite these efforts there is still 'a lot of glaucoma out there.' The London inner city eye survey conducted in Moorfields' backyard identified many new cases of treatable eye disease including glaucoma. ${ }^{4}$ Faced with probable public inertia it is up to health professionals to become more effective in identifying the disease.

How best to diagnose the early case? Screening for glaucoma implies formal surveys of known populations. This is limited by cost and is bound to be both expensive and patchy. Case finding is cheaper, easier, and can be continuous in the population (one normal blood pressure reading in a lifetime is insufficient to say that hypertension will never occur). There is still room for improvement in the three areas noted above. Firstly, by increasing public awareness. The knowledge that some racial groups (such as Afro-Caribbeans for primary open angle glaucoma ${ }^{5}$ ) have an above average risk should be disseminated throughout their communities. The positive relationship between lifestyle (lack of exercise and animal fat rich diet $^{6}$ ) to the development of ocular hypertension needs to be stressed. (The observation that IOP levels fall after a change in lifestyle offers a real chance of true ocular hypertension prophylaxis. ${ }^{7}$ ) Secondly, optometrists should be asked to test for glaucoma in all their patients, and not leave it to the current voluntary system with its inevitable patchiness. $^{8}$

Thirdly, the general practitioner should be given the wherewithal to test for glaucoma. This should include simple perimetric testing easy enough to be administered by the practice health auxiliary to all patients attending the surgery. Oculokinetic perimetry (OKP) fits this criterion, ${ }^{9}$ and could easily be used for this purpose. The original system has been modified in the light of clinical trials, and in this issue of the journal Mutlukan and colleagues describe further develop- ments. This sytem combines the qualities of low cost, ease of use, and speed with its ability to identify visual defects. It does not claim to be ideal and the authors acknowledge that there is still room for further improvement. As it stands it offers the chance of a 'waiting room test' for all adults attending the general practitioner surgery. The test must be an important advance towards the ideal of 'case finding for all' and be part of the tests performed in a 'well persons clinic' in the future.

What other case finding tests could be used in similar circumstances? Self tonometry could also be incorporated into the waiting room assault course for patients. ${ }^{10}$ The recent recognition that other preperimetric or hyperacuity measurements may detect visual damage at an even earlier (and presumably easier to treat) stage of glaucoma than OKP must require vision researchers to come up with similar easy to use tests ideal for the optician or general practitioner (the laptop motion sensitivity test shows promise in this regard $^{11}$ ). Finally, the cost of fundus imaging systems may fall sufficiently for them to appear in fundholding general practice surgeries. It is only when such tests are available for all can universal case finding and glaucoma detection be said to have arrived and the rate of annual increase in the blind register from glaucoma have a chance to decline.

R A HITCHINGS

Moorfields Eye Hospital,

City Road,

London EC1 2PD

Hitchings RA. Visual disability and the elderly. [Editorial] $B M \mathcal{F} 1989$; 298: 1126-7.

2 Jay J, Allen D. The benefit of early trabeculectomy versus conventional management in primary open angle glaucoma relative to severity of disease. Eye 1989; 3: 528-35.

3 Migdal CM, Hitchings RA, Gregory W. Effect of mean IOP levels on visual field preservation in treated glaucoma patients. (To be presented at the College of Ophthalmologists Annual Congress, Birmingham, 1993.)

4 Wormald RPL, Wright LA, Courtney P, Haines AP. Survey of eye health in an inner city GP practice. BMๆ 1992; 304: 1226.

5 Tielsch JM, Sommer A, Witt K, Katz J, Royall RM. Blindness and visual impairment in an American urban population. Arch Ophthalmol 1990; 108: impairm

6 Passo MS, Goldberg L, Elliott DL, VanBuskirk EM. Exercise training reduces intraocular pressure among subjects suspected of having glaucoma. Arch Ophthalmol 1991; 109: 1096-8.

7 Passo MS, Elliott DL, Goldberg L. Long term effect of exercise conditioning on intraocular pressure in glaucoma suspects. F Glaucoma 1992; 1: 39-41.

8 Tuck MW, Crick RP. Screening for glaucoma: age and sex of referrals and confirmed cases in England and Wales. Ophthalmol Physiol Opt 1992; 12: $400-4$.

9 Damato B, Chyla J, McClure E, Jay J, Allen D. A hand held OKP chart for the screening of glaucoma: preliminary evaluation. Eye 1990; 4: 632-7.

10 Groenhoff S, Draeger J, Deutsch C, Wiezorrek R, Hock B. Selftonometry: technical aspects of calibration and clinical application. Int Ophthalmol 1992; 16: 299-304.

11 Wu X, Wormald RPL, Fitzke F, Nagasubramanian S, Hitchings RA. Laptop computer perimetry for glaucoma screening. Invest Ophthalmol Vis Sci 1991; 32 (Suppl): 810 . 